\title{
The Murder of Therapy: Why Clients Don't Get Better
}

\author{
Steven Bell \\ Emeritus Professor of Psychology, Psychology Department, Berry College, Mt. Berry, 30149, Georgia, USA \\ *Corresponding Author: sbell@berry.edu
}

Copyright $@ 2014$ Horizon Research Publishing All rights reserved.

\begin{abstract}
This is an article describing and analyzing my four months working as a Psychologist in the Occupied Territories known as the West Bank, Palestine. While I speak of two families and two children, this is done to make the story easier to tell. Actually, I worked with several families and multiple children. I discovered the power and challenge of a collectivist culture to applying learning theory principles. The work of Professors Nathan Azrin (Azrin, 1974), Richard Foxx (Foxx, 1982), and Marc Gold (Gold, 1974) was basic to my therapeutic approach. Azrin and Foxx were able to bridge the gap between modifying the behavior of laboratory animals to the teaching of humans and their families to decrease negative actions and increase positive ones in two primary ways. In the instances reported in this paper parent of the individuals successfully though hesitantly raised their expectations and were taught to break down the tasks into more manageable steps. Marc Gold expressly focused on Moderately Intellectual Disabled Individuals. Where this paper is different from hundreds of other behavioral modification reports is the unique context of a collectivist Palestinian culture struggling to survive under a military occupation. The collectivist imperative required the mothers (who were cast by the culture into the primary distributors of rewards and task difficulty). Simultaneously, because of the military occupation the mothers were unable to travel (from Bethlehem to Jerusalem) to institutions and agencies which could have provided guidance and support.
\end{abstract}

Keywords Intellectual Disabilities, Overprotection, Learned Helpless, Collectivist Culture, Behavior Modification

\section{Introduction}

\subsection{The Problem}

Why don't folks get better? If one takes Herbert Spenser's advice and modifies it for psychologists working with folks from very different cultures you get: "There is a principle which is a bar against all information, which will keep you in everlasting ignorance - that principle is contempt prior to investigation." In my case the Murder of Therapy was an dual unawareness of: a) the Collectivist Arab culture and b) the inability of educated parents to acquire professional guidance and support to successfully help their Moderately Intellectual Disabled adult offspring.

\subsection{Another Problem}

How do I get your attention when so many other legitimate needs demand your time and resources? Sadly, one option might be to take the advice of Michael Corleone in Mario Puzo's, The Godfather. "Keep your friends close. Keep your enemies closer." If you are Jewish or Christian: there are 1.57 billion Muslims in the world. If you are Muslim, Israel has one of the most powerful armed forces in the world with a high probability of possessing and the capability to deliver over 100 nuclear weapons. This is an area of the world about which you might wish to know a little bit more.

\subsection{A Third Problem}

One of the things which did not get my attention was my concept of Truth. It was the greatest barrier to my understanding. It appeared to me that the completely irrational behaviors on the part of Palestinian families, namely, blocking therapeutic plans to change children's inappropriate behaviors were completely irrational. I learned more concretely about the power of culture to be a counter force to a successful therapeutic continuum.

\section{Culture}

Cultures are typically divided into two somewhat discrete categories: Collectivist and Individualist (Grief, 1994). While relatively large numbers of individuals vary from the norm, generally, people in individualist cultures, such as ours in the USA emphasize personal achievement at the expense of group goals. Collectivism and individualism deeply pervade cultures. I simply took my culture's stance for granted as the standard of Truth. In the USA, our deeply ingrained individualism can be illustrated by our aversion to car pooling - forcing us to reward it by creating High Occupancy Vehicle lanes in large cities.

In a Collectivist culture each person is encouraged to conform to do what is best for the group. The family's 
obligations for the common good are seen as more important than the rights of individuals - in my experience the rights of mothers to have some private life away from family obligations. In extreme conditions wanting to be independent or stand out is seen as shameful. Everyone must rely on others (nuclear family first) for support. In the case of Palestinians living in the West Bank, their collectivist culture was weakened by the geopolitical reality of Israel's occupation.

Prior to 1967 the West Bank (of the Jordan Valley) was controlled by Jordan. After the "six day" War, the West Bank fell into Israeli hands and control. In 1987 and again in 2000, the Palestinians attempted to "shake-off" (Intifada) the Israeli occupation. There was fatal violence (including suicide bombings) which led to a strict military occupation, severely limiting travel visas, and tightening of access to other countries into Israel and with the West Bank itself. In my brief time in Bethlehem getting into Jerusalem even with my US passport could take two hours. Traveling less than 40 kilometers from Bethlehem to Jericho was interrupted three times by Israeli military checkpoints turning an 80 minute round bus trip minute trip into four hours. For Palestinian civilians access to Jerusalem through the military checkpoints could take half the day or often not at all because the checkpoints were arbitrarily closed.

During my Sabbatical and Rotary International Grant period I was working in the Collectivist culture of the Israeli Occupied Territories, getting my chance to be a full-time Counseling-School psychologist again. Mostly, given the populations I was serving, I used a form of behavior modification (BMod) (D'Zurilla \& Goldfried, 1971) known currently as Applied Behavior Analysis (Gresham, Gansle, $\&$ Noell, 1993). It varies from other therapeutic methods by emphasizing the visible and measurable over the psycho dynamically oriented emphasis on the invisible. Given the limitations of the four individuals' insight and associative ability, I decided to change the behavior rather than the thoughts. Besides, as has been demonstrated with Cognitive Maps (Eden, 1992). If you change the outer behavior, the brain's associations change as well.

\section{Behavior Modification Principles}

- The Law of Readiness (Herrnstein, 1970), which says there are optimal times to teach and learn new behaviors; for example, using food as reinforcers during meals.

- The Law of Effect (Thorndike, 1927), wherein the consequences of a behavior strengthen or weaken the probability of its reappearing. If a behavior is reinforced, the likelihood that it will reoccur increases; for example, getting a snack after using the appropriate language by naming it. If a punishment follows a behavior, the likelihood of the behavior reappearing is lessened; for example, getting the silent treatment after you hit your brother
- The Premacke Principle (Danaher, 1974), where first, one withholds the things or opportunities the person normally finds rewarding. Then getting them is made contingent on the desired behavior. For example, Fadi loved walking with his grandmother and sitting on the porch swing with his grandfather. So we allowed going for a walk with grandmom or swinging on the porch with grandpop only when he asked using the appropriate language.

- Task analysis (Gold, 1974), wherein a complicated multistep process is broken down into manageable increments. For example, getting dressed.

The rationale for my using behavior modification rather than a cognitive behavioral approach is that the participants were essentially nonverbal; were not cooperative and had little insight. Also Behavior modification is more than twice as effective as psychotherapy in general: with a success rate as high as $80 \%$ - (Stern, \& Golden, 1977) symptom substitution notwithstanding. In traditional therapy $1 / 3$ of the people are likely get worse or to put it another way: you are as likely to get better if left alone.

\section{Role of Family}

It is well know that any form of therapy is enhanced or inhibited by the cooperation or noncooperation of the "family". Yet, my Individualistic orientation blocked my complete understanding of the power of family in the Collectivist culture. And herein lay the root of my challenge: to focus my time and skill - teaching primarily on the mothers - how to change her child's behavioral repertoire. This challenge was made even more insidious because I took for granted my Individualistic culture and was thus not familiar enough with the ground rules of a Collectivist culture. It was not until I realized the entire family - which is a lot of people in this fecund society - had to be brought in as stakeholders for success to begin and be sustained. Imagine a room full of parents, both sets of in- laws/grandparents, a smattering of uncle, aunts, nephews, nieces and cousins all yelling and interrupting each other in a language I barely understood.

\section{Role of Mother}

Complicating behavioral therapy was a lack of resources taken for granted in the USA. Infuriatingly, in the West Bank, there are many egregious, developing forces insidiously and systematically at work (Ilan, 2006): a 43 year military occupation blocking free movement in a multitude of ways within the country, interfaith religious tension, and a government based on tribal rather than democratic principles and, of course, piled on - a drought. The lack of a strong central government has meant there are no public laws allowing the education of handicapped children and youth.

Therefore, these disabled individuals must stay at home. 
Thus, the responsibility for education, counseling, therapy and for behavior change falls on the family - namely, the mother, but as I was soon to discover - the power was distributed into the nuclear and even extended family. Often times the mother found herself overwhelmed with the duties to her husband, aged parents, aged in- laws, unmarried children, married children, grandchildren, extended families ties and then all the responsibilities of running the home. Consequently, she became estranged from the best interests of her handicapped children. Much like the adage: "it's hard to remember you were sent to drain the swamp when you are up to you neck in alligators," the mother often was simply unable to carry out the therapeutic intent of a well developed straightforward behavioral plan - defaulting to giving reinforcers intermittently often without the child's compliance and doing for her children rather than making them do for themselves.

While using Applied Behavior Analysis with three families and their children I eventually realized the power of the Collectivist cultural of which I (coming from an individualist culture) was virtually unaware, in spite of two years studying Arab culture and language with face-to-face tutors. The fact that in spite of daily Rosetta Stone lessons, which drove my colleagues and wife out of their minds, my Arabic wasn't terrific and their English (which was many times better than my Arabic) confounded our plans. On one occasion I told a mother that she should ask for compliance only three times before removing the reinforcer. The mother heard "the child should say the target word three times before getting the reinforcer." Imagine how frustrating that was for the mother and the child.

The fact that there were no schools to help meant I was working in each family's home two times a week for several hours per session. I was able to see the mother, often the father and occasionally some members of the extended family interact with the four children.

\section{Culture}

In the Collectivist culture of the Arabs in the West Bank, one can easily find multiple generations of a family living in a layered "wedding cake" of a multistoried house. The first floor would house the in-laws, the second the nuclear family and the third the unmarried bachelors. There are certainly some wonderful advantages to this intergenerational living arrangement of grandparents and grandchildren living together. Our individualist culture could relearn a lot about honoring our senior citizens. I saw no nursing facilities or retirement homes in the West Bank.

A disadvantage in this culture is that Mom is often by-passed, ambushed and undercut by the well meaning father, siblings, grandparents and extended family - creating a major therapeutic challenge to the required tight behavior-reward system. These other stakeholders routinely ignored the rule of withholding reinforcers, e.g. snacks, walks, etc. contingent on behaviors such as language to express wants. It was not until I realized the power of the nuclear and extended family that my work with three moderately disabled adults and one autistic child began to be successful.

\section{Fadi's Language}

Fadi is a five-year-old boy who lost language at about a year and a half. He is solitary by choice and demands a high degree of order and consistency (he must walk on a certain side of the side walk to a certain distance). If one of his steps crosses "his" line in the cement, an ear piercing tantrum could last 20 minutes. He seems incapable of communicating with other people even when dire events are impinging on his life. Over a period of about five minutes, I saw him completely defenseless and silent as he was pummeled nearly to insensibility by two-year-old half his size.

His mother, Ghada, had agreed to only allow him to have a biscuit or a cup of tea when he used words to ask for them. The grandparents nodded in agreement that going for a walk or swinging would also be contingent on Fadi asking. We even were willing to accept "bidi" (I want) for any of the three reinforcers namely: going for a walk, swinging and/or getting snacks. After two weeks of restricting these "luxuries", no breakthrough occurred. One day his sister reported Fadi said "duda (ant)" so following the principle of "take what the client gives you" we surrounded him with: a jar of ants, pictures of ants to color, clay to mold into an ant. Yet, no progress beyond the one occasion of one word "duda" was made. I was befuddled. No snacks, walks or swings for two weeks, yet no words were being said. The Law of Effect was not working. Or so it seemed. Where were Edward L. Thorndike and B. F. Skinner when I needed them? Low and behold, at a family gathering, with head down, Grand mom admitted how badly she felt for poor Fadi so she was going for walks anyway. Emboldened, Grand pop revealed he was pushing Fadi on their outside swing without Fadi having to ask! The plan was going down in flames.

One of the rules of parenting, teaching and counseling is this: if a desired behavior is within the repertoire of the person then push. If it is not within the repertoire it would be cruel to withhold rewards. The trick is to know whether you have before you a "can't" client or a "won't" client. The mother and I were betting and hoping Fadi was a "won' $t$ ". As of this writing, now three months later, my efforts to discover if Fadi's case was a "can't' or a "won't" have been stymied by a lack of communication.

\section{Jamla's Activities of Daily Living}

The next cultural issue is highlighted by the second family with a twenty- six-year old moderately disabled adult daughter. Here, in this case, beside the ever present, extended-family-ambush is the increased amount of grieving a mother in a collectivist culture experiences. In this highly 
matriarchal society, she believes herself to be responsible for the entire family throughout their life spans (and before) or so it seems. Their failure is her failure and shame.

Basma and I worked on two issues: language development and creating multistep task analyses for: getting dressed; doing laundry; taking the dinner plate from table; not hitting her brother or niece; and using the toilet independently. We were using real power and leverage: favorite foods, having dessert, a drive in the car or watching TV. Further, we got rid of her childhood puzzles and beads replacing them with magazines appropriate to young adults (fashion magazines, make up, sport and muscle magazines).We used traditional learning principles: focus on tomorrow, not yesterday (Boker la ams). Accepting successive approximations (Skinner, 1963) toward the terminal goal, then demanding more. And most importantly - being consistent.

Basma is not the first parent experiencing guilt, anger, exhaustion, and misplaced sympathy (Kubler-Ross, 1972), unknowingly handicapping her grown daughter by allowing inappropriate behavior. Yet, by the absence of consistently applied consequences the family was creating a young adult who resisted training and responsibility. Jamla was allowed to point and grunt to get any foods outside of her reach. Her dinner plate was removed for her. Her laundry was done for her. She was often helped up the steps from her basement apartment to the dining area on the second floor. In both instances I was to discover the family was handicapping her growth by doing for her what they should have been encouraging her to do for herself. Here's an example: one day, Dad spent (wasted?) an hour trying to get her up the steps to the second floor for dinner including manually moving her legs up the first few steps. We were in the process of setting up a laborious, intensive, many-step task analysis when I suggested we all go upstairs for dinner and leave her alone leaving the natural consequence of being hungry to work. Mom and Dad (while being watched by the mother-in- law) were concerned (near hysteria) that if they didn't get her upstairs immediately, she would literally starve to death. I pleaded for their forbearance asking them to wait a few minutes more (several times) and it was reluctantly given (each time). Hearing Jamla's cries, a glum and silent dinner began. Ten minutes later, lo and behold, on her own she came up the steps and joined us. "Bravo, Jamla rang out!! What else can she do if we don't do for her?" Once they realized it was a "won't", here's what else

- progressing from grunts and points to a first word and in two weeks, five word sentences

- taking her plate, silver ware and glass from the table

- staying seated at the table throughout dinner

- not hitting her three-year-old niece

\section{The Mystery Unmasked: Conclusions}

Why don't folks get better? There are many challenges to being a counselor, teacher or psychologist with any person. One of the greatest challenges working to change anyone's behavior including your own, is reflecting over and over:

- Jumping to conclusions

- Is the problem behavior it a "can't" or a "won't"?

- Are the steps in the plan too great thereby overwhelming the person?

- Is the plan working?

- Could outside forces be blocking change? I am fifty pounds overweight. I eat while watching TV. I tried to move the TV from the kitchen. My kids objected.

You must understand (and understanding is the hardest part) we all live in a culture...it could be family, their extended family, their community, church, mosque, synagogue, country or even Facebook. This environment if collective can have more power to shape someone's behavior than their own best intentions. A sad example is the culture of Generational Poverty (Payne, 1996), which can crush the hardiest spirit. Remember the peer groups with whom you experimented as a teenager. When your parents told you, "birds of a feather flock together", they may have been rightly worried as they understood the power of the group. When I came to the Arab culture with only my truths, neglecting theirs, I met the enemy and he was me.

\section{REFERENCES}

[1] Azrin, N. (1974). Toilet training in less than a day ( $3^{\text {rd }}$ ed.). Simon \& Schuster.

[2] Greif, A. (1994). Cultural Beliefs and the Organization of Society: A Historical and Theoretical Reflection on Collectivist and Individualist Societies. The Journal of Political Economy, 102 (5), 912-50.

[3] Danaher, B. (1974). Theoretical Foundations and Clinical Applications of the Premack Principle: Review and Critique. Behavior Therapy, 5 (3), 307-24.

[4] D'Zurilla, T. J., Goldfried, M. R. (1971). Problem Solving and Behavior Modification. Journal of Abnormal Psychology, 78 (1), 107-26.

[5] Eden, C. (1992). On the Nature of Cognitive Maps. Journal of Management Studies, 29 (3), 261-65

[6] Foxx, R.M. (1982). Increasing Behaviors of Persons with Severe Retardation and Autism. Research Press, Champaign, IL

[7] Gold, M. (1974). Overview: Try another way. (Video). Retrieved from http://www.mnddc.org/extra/marc-gold1.htm 1.

[8] Gresham, F. M., Gansle, K.A., Noell, G. H. (1993). Treatment integrity in applied behavior analysis with children. Journal of Applied Behavioral Analysis, 26 (2), 257-63.

[9] Herrnstein, R. J. (1970). On the Law of Effect. Journal of the Experimental Analysis of Behavior, 13 (2), 243-66.

[10] Kubler-Ross, E. (1972). On Death and Dying. Journal of the American Medical Association, 221 (2), 174-79. 
[11] Pappe, I. (2006). The Ethnic Cleansing of Palestine. Oxford, England: Oneworld Publications Limited.

[12] Payne, R. K. (1996). A Framework for Understanding Poverty ( $4^{\text {th }}$ ed.). Highlands, TX: aha! Process Inc.

[13] Skinner, B. F. (1963). Operant Behavior. American Psychologist, 503-15.
[14] Stern, M. R., Golden, F. (1977). A Partial Evaluation of an Introductory Training for Psychiatric Nurses. American Journal of Community Psychology, 5 (1), 1-22.

[15] Thorndike, E. L. (1927). The Law of Effect. The American Journal of Psychology, 39 (1), 212-22. 